\title{
Retrieving vertical ozone profiles from measurements of global spectral irradiance
}

\author{
Germar Bernhard $^{1}$, Irina Petropavlovskikh ${ }^{2,3}$, and Bernhard Mayer ${ }^{4}$ \\ ${ }^{1}$ Biospherical Instruments Inc., San Diego, CA 92110, USA \\ ${ }^{2}$ Cooperative Institute for Research in Environmental Sciences (CIRES), University of Colorado, Boulder, CO 80309, USA \\ ${ }^{3}$ NOAA Earth System Research Laboratory, Global Monitoring Division, Boulder, CO 80305, USA \\ ${ }^{4}$ Ludwig-Maximilians-Universität, 80333 Munich, Germany
}

Correspondence: Germar Bernhard (bernhard@biospherical.com)

Received: 6 June 2017 - Discussion started: 25 July 2017

Revised: 24 October 2017 - Accepted: 6 November 2017 - Published: 20 December 2017

\begin{abstract}
A new method is presented to determine vertical ozone profiles from measurements of spectral global (direct Sun plus upper hemisphere) irradiance in the ultraviolet. The method is similar to the widely used Umkehr technique, which inverts measurements of zenith sky radiance. The procedure was applied to measurements of a high-resolution spectroradiometer installed near the centre of the Greenland ice sheet. Retrieved profiles were validated with balloonsonde observations and ozone profiles from the space-borne Microwave Limb Sounder (MLS). Depending on altitude, the bias between retrieval results presented in this paper and MLS observations ranges between -5 and $+3 \%$. The magnitude of this bias is comparable, if not smaller, to values reported in the literature for the standard Dobson Umkehr method. Total ozone columns (TOCs) calculated from the retrieved profiles agree to within $0.7 \pm 2.0 \%( \pm 1 \sigma)$ with TOCs measured by the Ozone Monitoring Instrument on board the Aura satellite. The new method is called the "GlobalUmkehr" method.
\end{abstract}

\section{Introduction}

The Umkehr method for determining the vertical distribution of ozone in the atmosphere was first introduced in the 1930s (Götz et al., 1934) and is now routinely applied to measurements taken with Dobson (e.g. Dütsch, 1959; Mateer and DeLuisi, 1992; Petropavlovskikh et al., 2005) and Brewer (McElroy and Kerr, 1995; Petropavlovskikh et al., 2011) spectrophotometers. The method is typically based on analysing ratios of zenith-sky radiances at two wavelengths in the ultraviolet (UV), one strongly and one weakly attenuated by ozone, that are measured at solar zenith angles (SZAs) between 60 and $90^{\circ}$. Here we explore using a similar optimal statistical approach to obtain vertical ozone information from measurements of spectrally resolved global irradiance, i.e. the irradiance received by a horizontal cosine collector from direct Sun and sky (upper hemisphere, from zenith to horizon). Such measurements were started by several groups in the early 1990s to monitor changes in UV radiation at the Earth's surface. These activities were motivated by concerns that decreases in atmospheric ozone concentrations, which were caused by ozone-depleting substances released by man into the atmosphere, could lead to increases in UV radiation with detrimental effects on human health, and terrestrial and aquatic ecosystems (e.g. Bais et al., 2015). Measurements of global spectral irradiance have been routinely performed by several UV monitoring networks sponsored by the National Science Foundation (NSF; http://uv. biospherical.com/), NOAA (http://www.esrl.noaa.gov/gmd/ $\mathrm{grad} / \mathrm{antuv} /$ ), the Network for the Detection of Atmospheric Composition Change (NDACC; http://www.ndsc.ncep.noaa. gov/), Environment Canada http://exp-studies.tor.ec.gc.ca/e/ ozone/ozonecanada.htm), the European Union (http://uvdb. fmi.fi/uvdb/), and others. The proposed method has the potential to make these long-term data sets available for assessing vertical ozone information in an approach similar to standard zenith-sky Umkehr retrievals. This is particularly interesting for locations where zenith-sky observations are not available. 
Compared to other methods (e.g. Lidar observations, Megie et al., 1977; balloon-sondes, and microwave spectrometers, Parrish et al., 1992; Waters et al., 2006), the Umkehr technique provides a relatively inexpensive way of measuring the vertical distribution of ozone in the atmosphere. The method is most sensitive to the altitude range of 20 to $45 \mathrm{~km}$ and has a resolution of about $10 \mathrm{~km}$ within this range. For midlatitude sites, Brewer Umkehr data have a precision of about $15 \%$ in the 20 to $40 \mathrm{~km}$ region, with larger departures outside this altitude range (McElroy and Kerr, 1995). Umkehr data are routinely used for monitoring the drift of sensors measuring the vertical distribution of ozone from space (Newchurch et al., 1987; DeLuisi et al., 1994; Miller et al., 1997; Krzyścin et al., 2009; Petropavlovskikh et al., 2005, 2011).

The use of measurements of global irradiance instead of zenith-sky radiance for Umkehr retrievals is of no advantage per se. First, global irradiance includes the direct solar beam, which is attenuated according to Beer's law and therefore does not contain information on the profile. Second, global irradiance includes photons received from directions close to the horizon and multiple-scattering effects are therefore not negligible. We will show that both challenges can be overcome, resulting in profiles of similar accuracy to those inverted from zenith-sky observations. The main advantage of the method presented here is that the vertical distribution of ozone can be derived for locations where no other groundbased data exist from which profiles could be calculated. The new method is called the "Global-Umkehr" method.

The Global-Umkehr method was tested using data from the NSF UV Monitoring Network (Booth et al., 1994), which has been measuring UV and visible global spectral irradiance $(290-600 \mathrm{~nm})$ at six high-latitude sites since 1990 . For this study we used data from Summit, Greenland $\left(72^{\circ} 35^{\prime} \mathrm{N}\right.$, $38^{\circ} 27^{\prime} \mathrm{W}, 3202 \mathrm{~m}$ a.s.1.), where ozone profiles have been routinely measured also by balloon-sondes. The method can also be applied to measurements at lower-latitude sites. We estimate that about 25 spectroradiometers that are part of the various UV monitoring networks mentioned earlier provide data of sufficient quality for the Global-Umkehr method. Some of these instruments were established in the early 1990s at locations around the globe, including the Arctic, North America, Hawaii, Europe, New Zealand, Australia, and Antarctica.

\section{Method}

\subsection{Retrieval method}

The retrieval method is based on the optimal estimation approach (Gauss-Newton method) developed by Rodgers (2000). In brief, the solution (i.e. the ozone concentration as a function of altitude or pressure) is determined iteratively with the matrix equation:

$\boldsymbol{x}_{i+1}=\boldsymbol{x}_{i}+\mathbf{S}_{i+1}\left[\mathbf{K}_{i}^{T} \mathbf{S}_{\varepsilon}^{-1}\left(\boldsymbol{y}-\boldsymbol{F}\left(\boldsymbol{x}_{i}\right)\right)-\mathbf{S}_{\mathrm{a}}^{-1}\left(\boldsymbol{x}_{i}-\boldsymbol{x}_{\mathrm{a}}\right)\right]$, where

$\mathbf{S}_{i+1}=\left(\mathbf{S}_{\mathrm{a}}^{-1}+\mathbf{K}_{i}^{T} \mathbf{S}_{\varepsilon}^{-1} \mathbf{K}_{i}\right)^{-1}$.

Equations (1) and (2) contain the following parameters:

$\boldsymbol{x}_{i}$ is the state vector of iteration $i$. In our implementation, it is defined as the average ozone concentration in 11 layers with a layer thickness of $5 \mathrm{~km}$.

$\boldsymbol{y}$ is the measurement vector, which is composed of ratios of global spectral irradiance $E(\lambda)$ measured at $310 \mathrm{~nm}$ (a wavelength strongly attenuated by ozone) and $337 \mathrm{~nm}$ (a wavelength weakly attenuated by ozone) for SZAs ranging between 70 and $90^{\circ}$.

$\boldsymbol{F}\left(\boldsymbol{x}_{i}\right)$ is the solution of the forward model (Sect. 2.3), which simulates the measurements using the state vector as input.

$\mathbf{K}_{i}$ is the Jacobian matrix of the partial derivatives of the forward model results and the state vector.

$\mathbf{S}_{\varepsilon}$ is the covariance matrix quantifying the uncertainty of the measurements.

$\boldsymbol{x}_{\mathrm{a}}$ is the a priori state vector. The iteration starts by setting $\boldsymbol{x}_{0}=\boldsymbol{x}_{\mathrm{a}}$.

$\mathbf{S}_{\mathrm{a}}$ is the covariance matrix pertaining to the a priori state vector.

$\mathbf{S}_{i+1}$ is the solution error covariance matrix at iteration $i+1$, which can be exploited to calculate the uncertainty of the retrieval.

We chose $310 \mathrm{~nm}$ as the lower wavelength because measurements at this wavelength are at least a factor of 50 larger than the spectroradiometer's detection limit of $0.001 \mathrm{~mW} \mathrm{~m}^{-2} \mathrm{~nm}^{-1}$ for all SZAs and ozone columns of interest. The upper wavelength of $337 \mathrm{~nm}$ was chosen because the temperature sensitivity of the ozone absorption cross section has a local minimum at about this wavelength (Bass and Paur, 1985). We also tested other wavelength pairs or combinations of several pairs of wavelengths - e.g. combinations of $E(305) / E(337) ; E(310) / E(337) ; E(325) / E(337)$ - when developing the method. We found that the use of multiple pairs improved the information content only minimally but increased the computational time considerably.

The SZA range chosen for Umkehr observations is a tradeoff between the additional information content resulting from a larger range and the risk that environmental conditions (e.g. clouds, ozone profile) may change substantially over the longer observation time that a larger SZA range requires. During development, we tried several SZA ranges and found that a range of 70 to $90^{\circ}$ is a good compromise. This observation is consistent with the conclusion by Petropavlovskikh 
et al. (2005) that information in the upper layers is not degraded by changing the SZA range from 60-90 to 70-90 in the standard zenith-sky Umkehr method. We also omitted observations with SZAs larger than $90^{\circ}$ because of potential systematic errors in the forward model results (Sect. 2.3) when the Sun is below the horizon. At the latitude of Summit, a SZA range of 70 to $90^{\circ}$ is available in spring between 27 March and 8 May and in autumn between 4 August and 15 September.

The Jacobian matrix $\mathbf{K}_{i}$ has the elements $\left[\mathbf{K}_{i}\right]_{m n}=$ $\left[\partial \boldsymbol{F}\left(\boldsymbol{x}_{i}\right)\right]_{m} /\left[\partial \boldsymbol{x}_{i}\right]_{n}$ and is calculated for every iteration step.

The measurement error covariance matrix $\mathbf{S}_{\varepsilon}$ is a diagonal matrix and is constructed by assuming that elements of the measurement vector have an uncertainty of $\sigma_{\varepsilon}=3 \%$ and are independent of wavelength and SZA:

$$
\left[\mathbf{S}_{\varepsilon}\right]_{m n}=\left\{\begin{array}{ll}
\sigma_{\varepsilon}^{2}[\boldsymbol{y}]_{m}[\boldsymbol{y}]_{n} & \text { for } m=n \\
0 & \text { for } m \neq n
\end{array} .\right.
$$

The value of $3 \%$ was chosen based on the uncertainty budget of the spectroradiometer installed at Summit (Sect. 2.2). The choice of $3 \%$ was further supported by analysing the residuals of the retrieval results $(\boldsymbol{y}-\boldsymbol{F}(\hat{\boldsymbol{x}}))$ where $\hat{\boldsymbol{x}}$ indicates the solution state vector after the final iteration.

A priori state vectors $\boldsymbol{x}_{\mathrm{a}}$ were constructed by combining balloon-sonde profiles for altitudes below $10 \mathrm{~km}$ and profiles measured by the Microwave Limb Sounder (MLS) on NASA's Aura satellite for altitudes above $10 \mathrm{~km}$ (see Sect. 2.5 for additional information on these profiles). Separate a priori profiles were used for processing data from spring (27 March-8 May) and autumn (4 August-15 September). Profiles for both seasons were constructed by calculating the median of a large number of sonde and MLS profiles measured during the two periods using data from the years 2004 to 2014.

The covariance matrix pertaining to the a priori state vector, $\mathbf{S}_{\mathrm{a}}$, was constructed as suggested by Bhartia et al. (2013):

$\left[\mathbf{S}_{\mathrm{a}}\right]_{m n}=\sigma_{\mathrm{a}}^{2}\left[\boldsymbol{x}_{\mathrm{a}}\right]_{m}\left[\boldsymbol{x}_{\mathrm{a}}\right]_{n} \exp (-|m-n| / d)$.

The parameter $\sigma_{\mathrm{a}}$ specifies the anticipated variability of the retrieved profiles about the a priori profile and can be interpreted as the relative standard deviation (SD) of the profiles' distribution. The correlation length $d$ was set to two, which is equivalent to $10 \mathrm{~km}$ for our definition of the state vector.

When $\sigma_{\mathrm{a}}$ is set to a small value (e.g. 0.1), the solution of the inversion becomes very sensitive to the a priori profile. In contrast, when $\sigma_{\mathrm{a}}$ is set to a large value, the solution is mostly determined by the measurements. Choosing the optimum value for $\sigma_{\mathrm{a}}$ is a trade-off between two competing effects: a large value of $\sigma_{\mathrm{a}}$ ensures correct inversion result even if the true profile deviates greatly from the a priori profile. On the other hand, a small value of $\sigma_{\mathrm{a}}$ reduces the risk that the retrieval result is grossly incorrect if measurements are affected by unanticipated errors.
We calculated profiles for $\sigma_{\mathrm{a}}=0.1$ and 0.4 and compare the results in Sect. 3. The value of $\sigma_{\mathrm{a}}=0.1$ was chosen by analysing the variability of MLS profiles relative to the spring and autumn a priori profiles introduced above. For Umkehr layers 3 to 7 (the layers to which the Umkehr method is most sensitive) the relative SDs calculated from the MLS profiles vary between 0.05 and 0.15 ; averaged over layers 3 to 7 , the relative $\mathrm{SD}$ is 0.12 for the spring and 0.09 for the autumn period. The value of $\sigma_{\mathrm{a}}=0.4$ was chosen as the other extreme. With this value, the a priori profile has little influence on the inversion result and the effect of errors in the measurement vector $\boldsymbol{y}$ becomes more prominent. The retrieval results depend technically on the ratio $\gamma \equiv\left(\sigma_{\varepsilon} / \sigma_{\mathrm{a}}\right)^{2}$ as opposed to $\sigma_{\mathrm{a}}$ (Bhartia et al., 2013). Because the measurement uncertainty $\sigma_{\varepsilon}$ is well defined, we discuss the results using $\sigma_{\mathrm{a}}$ instead of $\gamma$.

The iteration is repeated until two conditions are met: first, the norms of $\boldsymbol{x}_{i+1}$ and $\boldsymbol{x}_{i}$ must differ by less than $0.5 \%$, and second, the values of consecutive results of the cost function $\Psi(\boldsymbol{x})$ must agree to within $5.0 \%$, where

$\Psi(\boldsymbol{x})=(\boldsymbol{y}-\boldsymbol{F}(\boldsymbol{x}))^{T} \mathbf{S}_{\varepsilon}^{-1}(\boldsymbol{y}-\boldsymbol{F}(\boldsymbol{x}))+\left(\boldsymbol{x}_{\mathrm{a}}-\boldsymbol{x}\right)^{T} \mathbf{S}_{\mathrm{a}}^{-1}\left(\boldsymbol{x}_{\mathrm{a}}-\boldsymbol{x}\right)$.

These convergence criteria were adopted from Tzortziou et al. (2008). We confirmed that these criteria are also appropriate for our application by analysing changes of the two convergence metrics as a function of iteration $i$. The two criteria are always met in two to four iterations.

The uncertainty $e_{m}$ of each element of the solution's state vector was calculated according to Goering et al. (2005) from the diagonal elements of the solution error covariance matrix and the solution state vector:

$e_{m}=\frac{\sqrt{[\hat{\mathbf{S}}]_{m m}}}{[\hat{\boldsymbol{x}}]_{m}}$,

where the caret () above the symbols $\boldsymbol{x}$ and $\mathbf{S}$ indicates the values of $\boldsymbol{x}_{i}$ and $\mathbf{S}_{i}$ of the final iteration.

The performance of an inversion based on the optimal estimation approach is often assessed with the averaging kernel matrix $\mathbf{A} \equiv \hat{\mathbf{S}} \mathbf{K}_{i}^{T} \mathbf{S}_{\varepsilon}^{-1} \mathbf{K}_{i}$, which quantifies the sensitivity of the retrieved state $\hat{\boldsymbol{x}}$ to perturbations in the true state $\boldsymbol{x}$. For an ideal observing system, $\mathbf{A}$ is the identity matrix. In reality, the rows of the averaging kernel matrix are peaked with a finite width, which can be regarded as a measure of the vertical resolution of the retrieved profile. Similarity to the identity matrix, it indicates that the retrieval solution has been determined using the observations rather than the a priori information, and as such, the retrieval has provided new information about the actual state.

Elements of $\mathbf{A}$ can have large positive and negative values for layers where the ozone concentration is close to zero. To prevent this predicament, Bhartia et al. (2013) suggested illustrating the performance of the algorithm with relative averaging kernels (RAK or $\mathbf{A}_{\mathrm{R}}$ ), which quantify the relative 
change of the retrieved state $\hat{\boldsymbol{x}}$ to the perturbations in the true state $\boldsymbol{x} . \mathbf{A}_{\mathrm{R}}$ is defined by

$\left[\mathbf{A}_{\mathrm{R}}\right]_{m n}=[\mathbf{A}]_{m n} \frac{[\hat{\boldsymbol{x}}]_{n}}{[\hat{\boldsymbol{x}}]_{m}}$.

The optimal estimation technique provides several diagnostics in addition to the averaging kernels about the quality of the retrieved profile. The diagnostic used here is $d_{\mathrm{s}}$, which expresses the number of degrees of freedom for signal and indicates the number of useful independent observations in the measurement vector $\boldsymbol{y} . d_{\mathrm{s}}$ was calculated as suggested by Rodgers (2000) and Goering et al. (2005) from the singular values $\lambda_{m}$ of the error-weighted weighting function matrix $\widetilde{\mathbf{K}} \equiv \mathbf{S}_{\varepsilon}^{-1 / 2} \mathbf{K S}_{\mathrm{a}}^{-1 / 2}$ via

$d_{\mathrm{s}}=\sum_{m} \frac{\lambda_{m}^{2}}{1+\lambda_{m}^{2}}$.

The diagnostic $d_{\mathrm{S}}$ depends on $\mathbf{S}_{\mathrm{a}}$ and in turn on $\sigma_{\mathrm{a}}$. We will show in Sect. 3 that $d_{\mathrm{S}}$ is considerably smaller for profiles calculated with $\sigma_{\mathrm{a}}=0.1$ than 0.4 .

\subsection{Measurements}

The method was tested using measurements of global spectral irradiance performed at Summit with a SUV-150B spectroradiometer designed by Biospherical Instruments Inc. The instrument has a spectral resolution of $0.63 \mathrm{~nm}$, is part of the US National Science Foundation's Arctic Observing Network, and contributes data to NDACC. The expanded uncertainty (coverage factor $k=2$, equivalent to uncertainties at the $2 \sigma$-level or a confidence interval of $95 \%$ ) of global spectral irradiance measurements for wavelengths between 310 and $337 \mathrm{~nm}$ is between 6.0 and $6.7 \%$. More information on the instrument is provided by Bernhard et al. (2008) and a detailed uncertainty budget is available at http://uv. biospherical.com/Version2/Uncertainty_SUV150B.pdf.

Data used in this paper are from the version 2 data edition (Bernhard et al., 2004) and are corrected for the cosine error of the instrument's entrance optics. The wavelength mapping was determined with a Fraunhofer-line correlation method and the wavelength uncertainty $(k=2)$ of processed data is $0.02 \mathrm{~nm}$. Measured spectra and spectra calculated with the forward model (Sect. 2.3) were convolved with a triangular function of $2 \mathrm{~nm}$ bandwidth to further reduce uncertainties resulting from potential wavelength shifts between measured and modelled spectra.

The SUV-150B is a scanning instrument, which measures each wavelength at a different time. The time required to scan between 310 and $340 \mathrm{~nm}$ is about $140 \mathrm{~s}$. Changing cloud condition will therefore affect the ratio of measurements at these wavelengths and in turn the accuracy of the retrieval result. The effect of clouds on the ratio of $E(310) / E(337)$ can be reduced using measurements of a filtered photodiode, which is illuminated via a beam splitter located between the entrance optics and monochromator of the SUV-150B system. The sensitivity of the diode is centred at $330 \mathrm{~nm}$ and measurements are preformed continuously during the recording of spectra. Because attenuation by thin clouds is fairly uniform in the 310 to $337 \mathrm{~nm}$ range (Seckmeyer et al., 1996), measurements of the photodiode can be used to correct for variable cloud attenuation. Specifically, spectral measurements at $\lambda=310 \mathrm{~nm}$ or $\lambda=337 \mathrm{~nm}$ are multiplied with a correction factor $C(\lambda, t)$, defined as

$C(\lambda, t)=\frac{D_{C}(\theta(t))}{D(t)}$,

where $t$ is the time of the spectral measurement, $\theta(t)$ is the SZA at time $t$, and $D(t)$ is the measurement of the photodiode at time $t . D_{C}(\theta(t))$ is the hypothetical clear-sky photodiode measurement at time $t$. The function was parameterized as a function of SZA using measurement of the photodiode obtained during clear skies. Clear-sky periods were determined based on temporal variability using the method described by Bernhard et al. (2008). The correction takes into account that the SZA changes between measurements at 310 and $337 \mathrm{~nm}$. This technique cannot be applied in the presence of optical thick clouds which increase ozone absorption of tropospheric ozone due to path length enhancement (Mayer et al., 1998). This restriction does not apply to Summit, where clouds are always optically thin (Bernhard et al., 2008). Measurement vectors were inverted both with and without the cloud correction, and results are compared in Sect. 3.2.

Spectral irradiances at 310 and $337 \mathrm{~nm}$ were calculated for all spectra measured during a given period of Umkehr observations and interpolated to a common SZA grid (70, 75, 80, $85,87,88,89$, and $90^{\circ}$ ) using an approximating (smoothing) spline. Compared to an interpolating spline, an approximating spline has the advantage of reducing noise in the measurement vector further. Tests indicated that retrieval results do not change significantly by adding measurements at additional SZAs.

The measurement vector is only constructed from spectra measured in the afternoon (between 15:00 and 20:00 UTC) because solar measurements have gaps in the morning when the system performs diagnostics scans with internal lamps (wavelength and irradiance standards).

\subsection{Forward model}

Forward modelling was performed with Version 1.01 of the pseudospherical discrete ordinate (SDISORT) radiative transfer solver of the UVSPEC/libRadtran model (Mayer and Kylling, 2005). The number of streams was set to 12. The model's results are spectra of global irradiance. Model input parameters include the extraterrestrial spectrum (as defined by Bernhard et al. (2004) and available at http://uv.biospherical.com/Version2/Paper/ 2004JD004937-ETS_GUEYMARD.txt), surface albedo, at- 
mospheric pressure, and the ozone absorption cross section (Bass and Paur, 1985). While more accurate ozone absorption cross sections are now available (Gorshelev et al., 2014; Orphal et al., 2016), we used Bass and Paur (1985) data to facilitate validation with OMI total ozone column measurements, which are also based on Bass and Paur (1985). The surface albedo at Summit was set to 0.97 in good agreement with recent measurements (Carmagnola et al., 2013). Aerosol optical depth was set to stratospheric background conditions. Atmospheric pressure and profiles of gases other than ozone $\left(\mathrm{O}_{2}, \mathrm{H}_{2} \mathrm{O}, \mathrm{CO}_{2}\right.$, and $\left.\mathrm{NO}_{2}\right)$ were taken from the Air Force Geophysics Laboratory (AFGL) atmospheric constituent profile for subarctic summer (Anderson et al., 1986), which defines the atmosphere at 51 levels. The vertical distribution of ozone in this standard profile was replaced with the profile defined by the state vector $\boldsymbol{x}_{i}$ and updated in every iteration.

The SDISORT solver has been successfully validated using data of the NSF UV Monitoring Network (e.g. Bernhard et al., 2004, 2008) and for a large range of conditions at other sites (e.g. Mayer and Kylling, 2005, and references therein). However to the best of our knowledge, rigorous validation for the large SZAs required for Umkehr retrievals has not been conducted. The pseudospherical approximation used by SDISORT correctly describes the attenuation of the direct beam in spherical geometry but the diffuse radiance is computed in plane-parallel geometry (Mayer et al., 2015). This approximation can lead to significant errors at large SZAs (Petropavlovskikh et al., 2000; Emde and Mayer, 2007). To quantify these errors for our application, we have compared spectra of global irradiance calculated with SDISORT with the spherical solver of the MYSTIC (Monte Carlo code for the phYSically correct Tracing of photons In Cloudy atmospheres) model, which fully solves the spherical geometry without any approximations (Mayer, 2009). Both models were run with the same set of input parameters (AFGL subarctic summer with a priori ozone profile for spring at Summit) for wavelengths between 307 and $313 \mathrm{~nm}$ and between 334 and $340 \mathrm{~nm}$ in $0.5 \mathrm{~nm}$ steps. The MYSTIC model was run with 84 million photons per wavelength and per SZA, resulting in photon noise of less than $0.5 \%$ at $\mathrm{SZA}=90^{\circ}$ (worst case). Resulting spectra of both models were convolved with a triangular function of $2 \mathrm{~nm}$ bandwidth to further reduce noise and to be consistent with the method used in the Umkehr code.

Figure 1a shows the ratio of SDISORT and MYSTIC spectra calculated for the eight SZAs used in our implementation of the Global-Umkehr method. SDISORT overestimates spectral irradiances relative to MYSTIC at all wavelengths and SZAs. For SZA $\leq 88^{\circ}$, the bias is less than $2 \%$ but increases to up to $6.5 \%$ for $\mathrm{SZA}=90^{\circ}$. For the Umkehr retrieval, only the ratio $q(\theta) \equiv \frac{E(310, \theta)}{E(337, \theta)}$ is important where $\theta$ again indicates the SZA. The ratio $R(\theta) \equiv \frac{q_{\text {SDISORT }}(\theta)}{q_{\text {MYSTIC }}(\theta)}$ resulting from calculating $q(\theta)$ with SDISORT and MYSTIC is
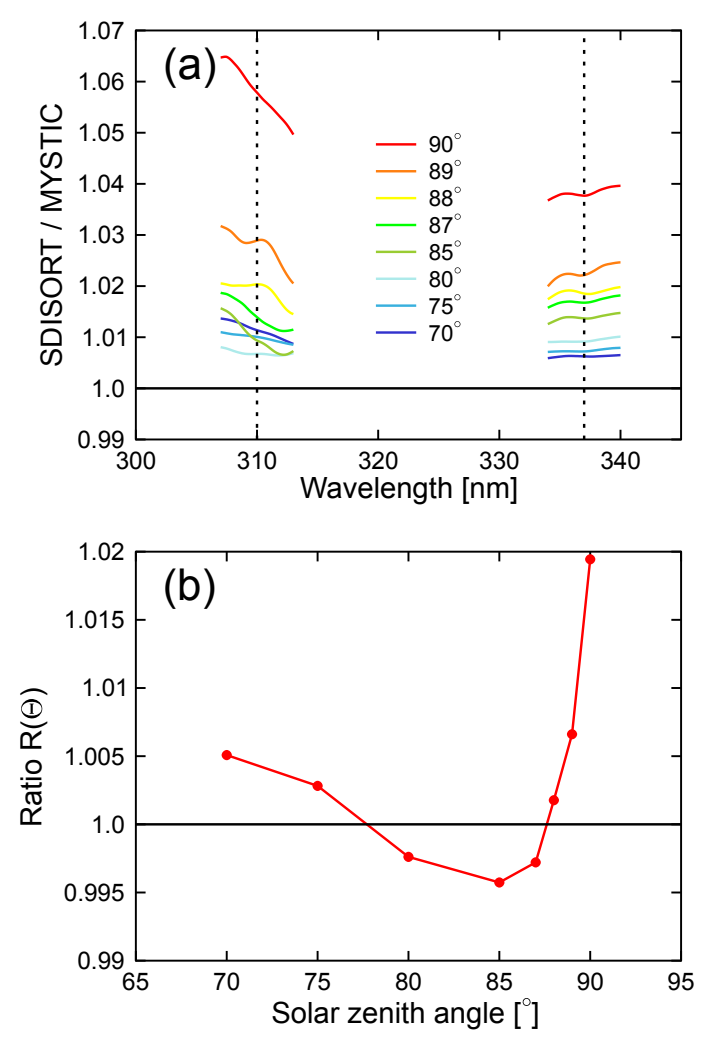

Figure 1. Comparison of results calculated with the SDISORT and MYSTIC models. (a) Ratio of SDISORT and MYSTIC spectra calculated for eight SZAs (see legend). (b) Ratio $R(\theta)$. See text for definition.

shown in Fig. 1b. $R(\theta)$ ranges between 0.998 at $80^{\circ}$ and 1.019 at $90^{\circ}$. Calculations with the MYSTIC model can be considered the most accurate results attainable because the Monte Carlo code does not use approximations. The model has been validated by comparison with other spherical radiative transfer models and by simulating the radiance distribution of the sky during a total solar eclipse. For such calculations, a spherical solver without approximations is required because light entering the atmosphere more than $1000 \mathrm{~km}$ away may impact the radiance in the centre of the umbral shadow (Emde and Mayer, 2007).

Relative to MYSTIC, SDISORT overestimates $q(\theta)$ for SZA larger than $88^{\circ}$. In our Umkehr code, we scale the results of the forward model with $1 / R(\theta)$ to account for the bias of the SDISORT model. Note that the MYSTIC model is too slow to be used for Umkehr retrievals: the calculation of the eight spectra used for Fig. 1a required a run time of over 3 days.

The forward model requires that the vertical structure of the atmosphere is defined as a function of altitude. The association between altitude and pressure is defined in the AFGL profile and this relationship may differ from the actual pressure profile at the time of Umkehr observation. Because our measurements do not allow the pressure profile to be recon- 

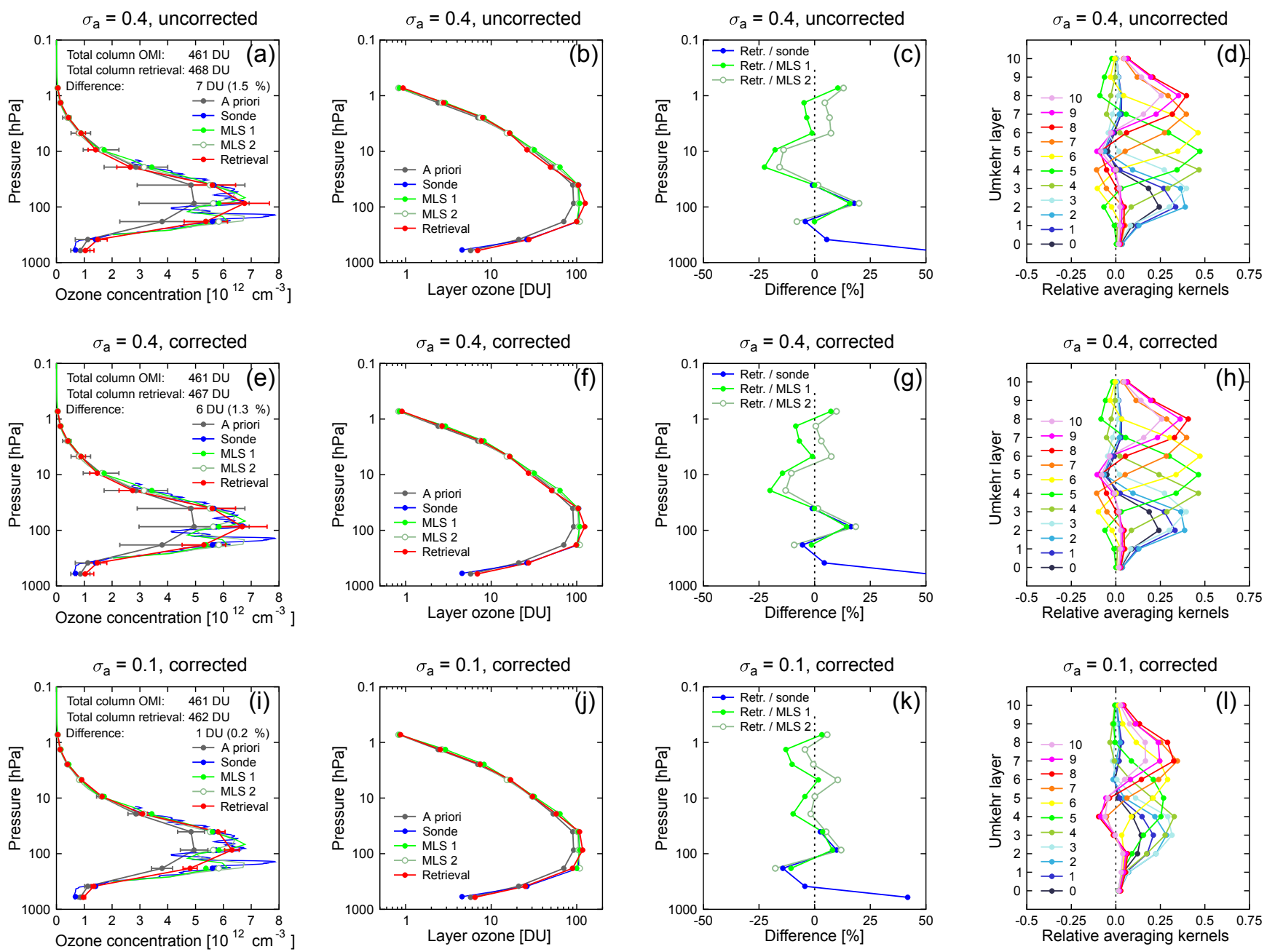

Figure 2. Validation of the ozone profile retrieved for 19 April 2014. (a-d) Results for $\sigma_{\mathrm{a}}=0.4$ and uncorrected forward model. (e-h) Results of $\sigma_{\mathrm{a}}=0.4$ and corrected forward model. (i-l) $\sigma_{\mathrm{a}}=0.1$, and corrected forward model. First column: ozone concentration as a function of pressure for a priori profile (grey), balloon-sonde profile (blue), MLS profile for day of retrieval (MLS 1, dark green), MLS profile of the following day (MLS 2, light green), and retrieved profile (red). Solid or open circles indicate, for each data set, ozone concentrations averaged over each of the 11 Umkehr layers defined in Table 1. Grey error bars indicate the diagonal elements of $\mathbf{S}_{\mathrm{a}}$. Red error bars indicate the uncertainty of the retrieval $e_{m}$. TOCs measured by OMI and calculated from the retrieved profile are indicated in the legend. Second column: layer ozone as a function of pressure for a priori profile, balloon-sonde profile, MLS profile for day of retrieval, MLS profile of the following day, and retrieved profile. Third column: difference between the retrieval and sonde, MLS 1 and MLS 2 data averaged over each Umkehr layer. Fourth column: relative averaging kernels.

structed, we report all ozone profiles as a function of pressure and compare the retrieved profile with sonde and MLS profiles, which are also provided as a function of pressure. The standard zenith-sky Umkehr technique (Petropavlovskikh et al., 2005) uses a similar approach. Table 1 provides altitude and pressure ranges for each Umkehr layer. Note that Layer 0 starts at the elevation of Summit (3202 m).

\subsection{Validation method}

The retrieved Umkehr profiles were validated using ozone profiles measured at Summit with balloon-sondes by
NOAA/GMD (Oltmans et al., 2010) and ozone profiles provided by MLS on Aura. Sondes are typically launched between 12:00 and 20:00 UTC. MLS measures thermal emissions from rotational lines of ozone through the limb of the atmosphere. Ozone measurements have a vertical range of $12-73 \mathrm{~km}$ with a vertical resolution of $2-3 \mathrm{~km}$ below $65 \mathrm{~km}$. The horizontal resolution is about $200 \mathrm{~km}$ and the accuracy is about $5-10 \%$ between 16 and $60 \mathrm{~km}$ (Froidevaux et al., 2008). The average horizontal distance between the locations of Summit and MLS data is $160 \mathrm{~km}$. Sonde and MLS profiles were downloaded from ftp://ftp.cmdl. noaa.gov/ozwv/Ozonesonde/Summit,\%20Greenland/ and 

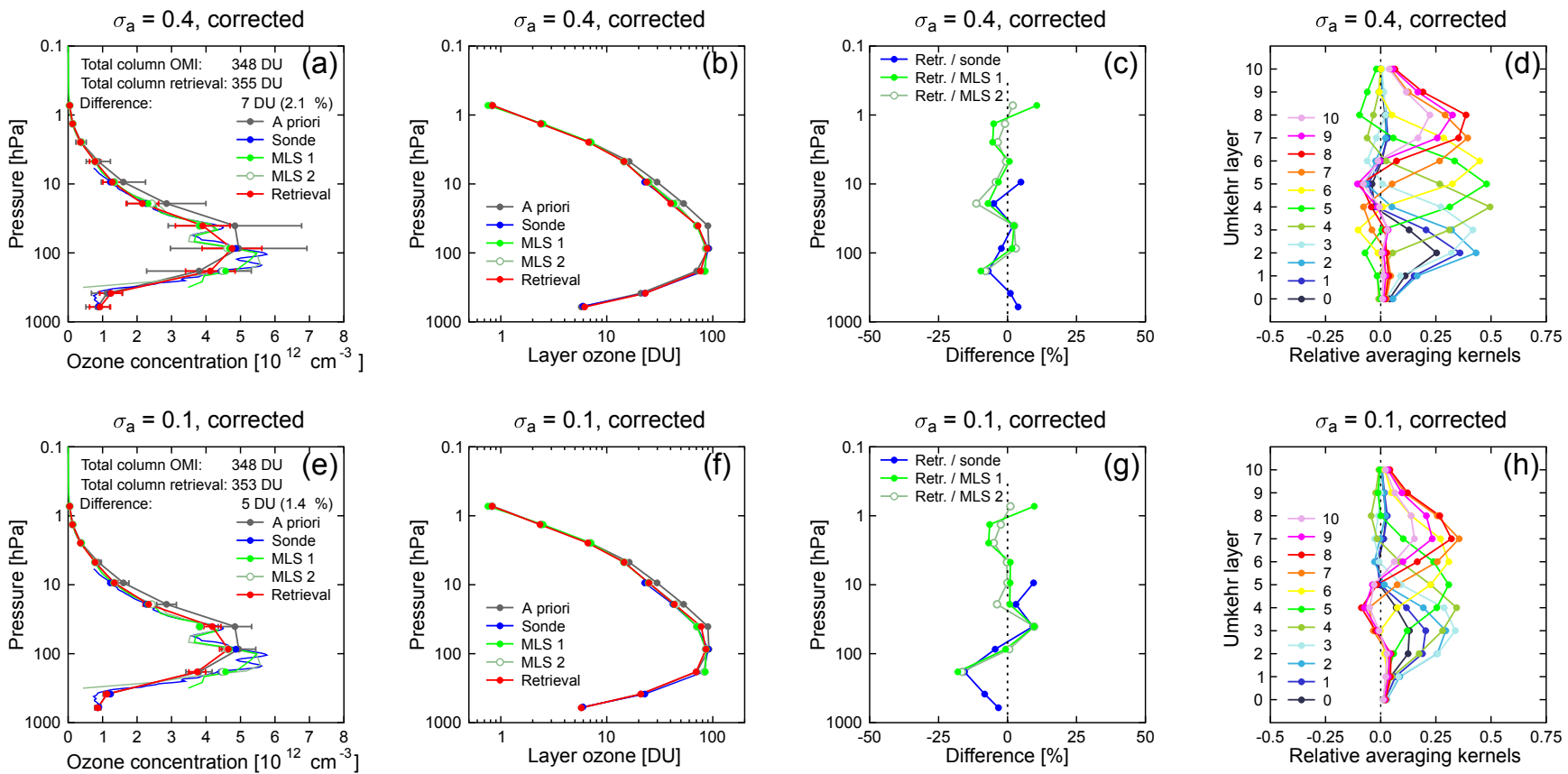

Figure 3. Validation of ozone profile retrieved for 11 April 2007. (a-d) Results of $\sigma_{\mathrm{a}}=0.4$ and corrected forward model. (e-h) $\sigma_{\mathrm{a}}=0.1$, and corrected forward model. (a, e) Ozone concentration as a function of pressure. (b, f) Layer ozone as a function of pressure. (c, $\mathbf{g}$ ) Difference between the retrieval and sonde, MLS 1 and MLS 2 data sets averaged over each Umkehr layer. (d, h) Relative averaging kernels. Labelling of the different data sets is identical to that of Fig. 2.
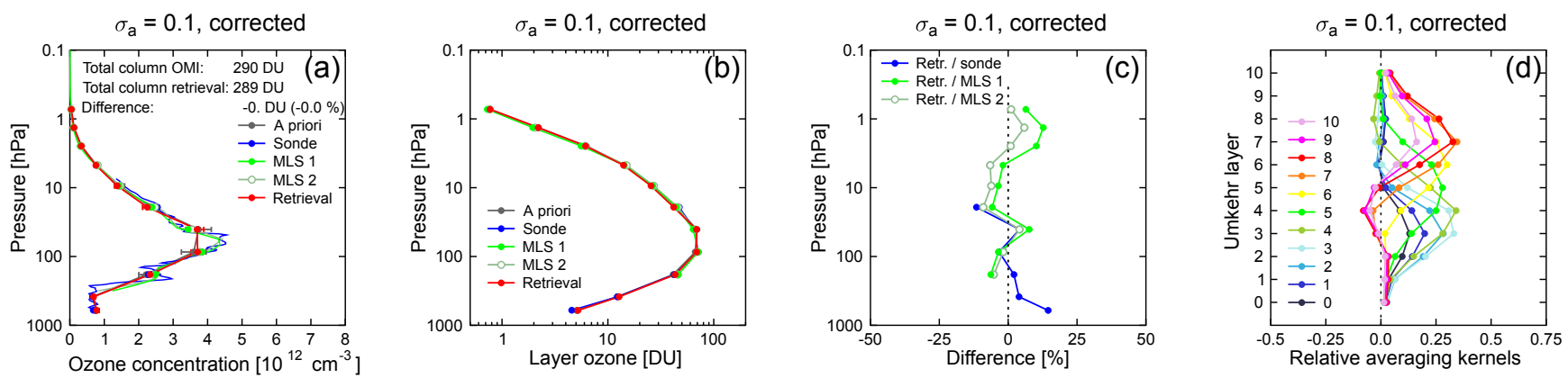

Figure 4. Validation of ozone profile retrieved for 14 August 2009. The retrieved profile was calculated with $\sigma_{\mathrm{a}}=0.1$ using the corrected forward model. (a) Ozone concentration, (b) layer ozone, (c) difference between the retrieval and sonde, MLS 1 and MLS 2 data sets averaged over each Umkehr layer, (d) relative averaging kernels. Labelling of the different data sets is identical to that of Fig. 2.

http://avdc.gsfc.nasa.gov/pub/data/satellite/Aura/MLS/V04/ L2GPOVP_Prof/O3/Summit/, respectively. Sonde profiles are only available for 2 to 4 days per month, whereas MLS profiles are available on a daily basis. MLS measurements at Summit take place either between 05:28 and 06:26 UTC or between 14:11 and 15:10 UTC. There is only one data file per day in the NASA archive.

The total ozone column (TOC) was calculated from the retrieved Umkehr profiles and compared with measurements from the Ozone Monitoring Instrument (OMI) on board NASA's Aura spacecraft. OMI overpass data were downloaded from http://avdc.gsfc.nasa.gov/index.phpfisite= 1593048672\&id=28. OMI data use the Bass and Paur (1985) ozone absorption cross section (David Haffner, NASA, personal communication) like the forward model.

Good validation results can only be expected if the actual ozone profile does not change over the period of Umkehr observations. We therefore only considered periods in which the TOC measured by OMI did not change by more than 20 DU between 15:00 UTC on the day of the comparison and the first observation on the following day. This criterion ensures that changes in the ozone profile remain below about $4 \%$ for all Umkehr layers. Retrieved Umkehr profiles were compared with the sonde profile measured on the same day 
Table 1. Assignment of Umkehr layers.

\begin{tabular}{lrr}
\hline $\begin{array}{l}\text { Umkehr } \\
\text { layer }\end{array}$ & $\begin{array}{r}\text { Altitude range } \\
\text { forward model }(\mathrm{km})\end{array}$ & $\begin{array}{r}\text { Pressure } \\
\text { range }(\mathrm{hPa})\end{array}$ \\
\hline 10 & $50.0-55.0$ & $0.987-0.537$ \\
9 & $45.0-50.0$ & $1.82-0.987$ \\
8 & $40.0-45.0$ & $3.40-1.82$ \\
7 & $35.0-40.0$ & $6.61-3.40$ \\
6 & $30.0-35.0$ & $13.4-6.61$ \\
5 & $25.0-30.0$ & $27.8-13.4$ \\
4 & $20.0-25.0$ & $59.0-27.8$ \\
3 & $15.0-20.0$ & $126.0-59.0$ \\
2 & $10.0-15.0$ & $267.7-126.0$ \\
1 & $5.0-10.0$ & $541.0-267.7$ \\
0 & $3.202-5.0$ & $664-541$ \\
\hline
\end{tabular}

(if available) and with the MLS profiles measured on this day (labelled "MLS 1" in the following) as well as the next day (labelled "MLS 2").

\section{Results}

We first show retrieval results for 3 sample days with greatly different conditions and compare these results with profiles measured by balloon-sondes and MLS (Sect. 3.1). We then discuss in Sect. 3.2 statistics for all profiles that were retrieved under sufficiently stable conditions (variation in total ozone of less than $\pm 20 \mathrm{DU}$ ).

\subsection{Comparison with balloon-sonde and MLS profiles - sample profiles}

\subsubsection{Validation for 19 April 2014}

Figure 2 compares the retrieved ozone profile for 19 April 2014 with the a priori balloon-sonde and MLS profiles. OMI measured a TOC of 461 DU on this day, which was the third highest TOC of the data set and the highest TOC of days when balloon-sonde data were available. Therefore, the profile represents one of the highest departures from the spring a priori profile.

Results are shown for three sets of retrieval parameters: (1) $\sigma_{\mathrm{a}}=0.4$, forward model, not corrected (top row of Fig. 2); (2) $\sigma_{\mathrm{a}}=0.4$, forward model, corrected by scaling with $1 / R(\theta)$ (centre row of Fig. 2); and (3) $\sigma_{\mathrm{a}}=0.1$, forward model, corrected (bottom row of Fig. 2). For each set of parameters, we show profiles of ozone concentrations (first column of Fig. 2), layer ozone (second column of Fig. 2), the difference between the retrieved profile and the profiles measured by sondes and MLS (third column of Fig. 2), and the relative averaging kernels (RAKs) of the retrieval (fourth column of Fig. 2).

Layer ozone (Fig. 2b, f, and j) was calculated by integrating average ozone concentrations of each Umkehr layer over height. Note that ozone concentrations (Fig. 2a, e, and i) are plotted on a linear scale to highlight differences in the troposphere and lower stratosphere, while layer ozone (Fig. 2b, f, and j) is plotted on a logarithmic scale to better distinguish differences in the upper stratosphere.

Figure 2c, g, and k shows differences in the average ozone concentrations for the 11 Umkehr layers. Two MLS data sets are considered. The data set labelled MLS 1 is from the same day as the retrieval, while the data set labelled MLS 2 is from the following day.

When plotting ozone concentrations on a linear scale (Fig. 2a, e, and i), results for the three sets of parameters look similar. As expected, the resolution of the retrieval is not sufficient to capture the large fluctuation in the ozone concentrations between about 100 and $300 \mathrm{hPa}$ indicated by sonde and MLS measurements. Furthermore, the retrieved profiles overestimate the ozone concentration at the peak of the profile at about $100 \mathrm{hPa}$ and underestimate the profile in the 7 to $28 \mathrm{hPa}$ range (layers 5 and 6 ). The difference of $-22.5 \%$ between the retrieval and MLS 1 seen in Fig. 2c for Layer 5 is one of the largest negative biases of all profiles processed. This large bias may partially be caused by errors in the measurement vector due to clouds (the photodiode used for cloud correction was not available on this day). The large deviation of $52 \%$ for Layer 0 is not surprising considering that this layer is only $1.8 \mathrm{~km}$ thick and the sensitivity of the Umkehr method to ozone concentrations close to the surface is poor.

The bias of the retrieval becomes smaller when the forward model is corrected for the systematic error resulting from the pseudospherical approximation (compare Fig. 2c and $\mathrm{g}$ ), indicating that the correction is appropriate.

The smallest difference between the retrieval on one hand and sonde and MLS measurements on the other is observed for $\sigma_{\mathrm{a}}=0.1$ (Fig. $2 \mathrm{k}$ ). This suggests that a relatively small value for $\sigma_{\mathrm{a}}$ is advantageous even though the sample profile deviates considerably from the a priori profile. For layers 5 to 9 , the magnitude of the bias is comparable in magnitude to the difference between the two MLS profiles, suggesting that a portion of the bias could be due to changes in the ozone profile occurring during the period of Umkehr observations.

When $\sigma_{\mathrm{a}}$ is set to 0.4 , the RAKs of layers 3 to 7 peak at the correct layer and drop to zero within two layers, suggesting that ozone concentrations in this altitude range can be easily resolved (Fig. $2 \mathrm{~d}$ and h). In contrast, RAKs for layers 0,1 , and 2 are similar and peak at about the same altitude. Hence, ozone concentrations in these layers cannot be easily separated. The altitude resolution of the standard zenith-sky Umkehr method is also poor in these layers, and results for layers 0 and 1 are typically combined when reporting data. RAKs for layers 8-10 peak at the same altitude, indicating that ozone concentrations above the $3 \mathrm{hPa}$ level (about $45 \mathrm{~km}$ ) cannot be resolved and the retrieval is predominantly driven by the a priori profile. This is not surprising considering the small ozone concentrations in these layers. Also, the 
traditional zenith-sky Umkehr method has little sensitivity at these altitudes.

When $\sigma_{\mathrm{a}}$ is set to 0.1 , the RAKs become rather broad (Fig. 21). The solution is therefore more determined by the a priori profile than the observations. The reduced importance of the measurements is also reflected in the value of $d_{\mathrm{s}}: d_{\mathrm{s}}$ is 3.02 for $\sigma_{\mathrm{a}}=0.4$ and 2.15 for $\sigma_{\mathrm{a}}=0.1$.

TOCs calculated from the retrieved profiles agree well with the OMI measurements and depend only little on the choice of retrieval parameters: absolute and relative biases are $7 \mathrm{DU}(1.5 \%)$ for parameter set (1), $6 \mathrm{DU}(1.3 \%)$ for set (2), and $1 \mathrm{DU}(0.2 \%)$ for set (3).

\subsubsection{Comparison for 11 April 2007}

Figure 3 shows results for 11 April 2007. On this day, ozone concentrations measured by sonde and MLS were consistently below the a priori profile between 5 and $100 \mathrm{hPa}$, but between 100 and $300 \mathrm{hPa}$, the actual profile exceeded the a priori. Figure $3 \mathrm{a}-\mathrm{d}$ shows results calculated with $\sigma_{\mathrm{a}}=0.4$, while calculations for Fig. 3e-h used $\sigma_{\mathrm{a}}=0.1$. The forward model was corrected by scaling with $1 / R(\theta)$ in both cases. Note that the MLS 1 and MLS 2 data sets are almost identical, indicating that the actual ozone profile was constant over the observation period. RAKs are very similar to those for 19 April 2014 (compare Fig. 2h with Fig. 3d and Fig. 21 with Fig. 3h).

For both settings of $\sigma_{\mathrm{a}}$, the retrieved profile is narrower than the a priori profile and matches the MLS profile almost ideally for layers 3-9. This is an example of the retrieval result not simply being the a priori profile scaled with a constant factor. Instead, the information contained in the measurement vector is sufficient to modify the shape of the profile to match the actual, narrower shape. However, like in the case of the first example, the resolution of the Umkehr method is not sufficient to reproduce the fluctuation of the actual ozone profile between 70 and $300 \mathrm{hPa}$. The most obvious difference between the results calculated with $\sigma_{\mathrm{a}}=0.4$ and 0.1 is the difference at $183 \mathrm{hPa}$ (Layer 2). Because the Umkehr method has little sensitivity at this pressure level, the retrieved ozone concentration is mostly determined by the a priori profile for $\sigma_{\mathrm{a}}=0.1$ (Fig. $3 \mathrm{~g}$ ). In contrast, when setting $\sigma_{\mathrm{a}}=0.4$, measurements "pull" the retrieval to the higher concentrations of the actual profile, resulting in a smaller bias relative to sonde and MLS data (Fig. 3c). The TOCs of both retrievals agree to within $7 \mathrm{DU}$ (or $2.1 \%$ ) with OMI.

\subsubsection{Comparison for 14 August 2009}

The third example (Fig. 4) shows results from $14 \mathrm{Au}-$ gust 2009 when the ozone profile was almost identical with the autumn a priori profile. Note that this a priori profile is considerably below that for spring (e.g. Fig. 3d). Calculations were performed with $\sigma_{\mathrm{a}}=0.1$ and the corrected forward model. Results agree with sonde and MLS profiles to within $\pm 13 \%$ for layers $1-10$ and the TOC of the retrieval is virtually identical to the OMI measurement. The effect of changing $\sigma_{\mathrm{a}}$ from 0.4 to 0.1 are similar for spring and autumn profiles and results for $\sigma_{\mathrm{a}}=0.4$ were therefore omitted in Fig. 4.

In summary, Umkehr profiles replicate the general pattern in the sonde and MLS data but cannot resolve the fine structure in the ozone distribution, in particular below $100 \mathrm{hPa}$. The relatively poor resolution in the troposphere and lower stratosphere is similar for the standard zenith-sky Umkehr method.

\subsection{Comparison with balloon-sonde and MLS profiles - statistics}

While the results for the three profiles discussed above are promising, they do not allow a comprehensive assessment of the Global-Umkehr technique. To fully validate the method, we compared a large number of sonde and MLS profiles with our retrievals using measurements from the years 2004 to 2014, and calculated statistics. We only considered periods in which the TOC was constant to within $\pm 20 \mathrm{DU}$ as indicated by OMI. This criterion restricted the number of comparisons with sonde profiles to 57 and with MLS profiles to 552. Data were processed with and without the model correction discussed in Sect. 2.3 and with and without the cloud correction, discussed in Sect. 2.2. The latter correction requires measurements of the photodiode internal to the SUV-150B instrument. Unfortunately, these measurements were not available during all days, reducing the number of retrieval-sonde and retrieval-MLS comparisons to 38 and 396, respectively. Results from layers 0 and 1 and layers 2 and 3 were combined because of the poor vertical resolution of the Umkehr methods in the troposphere and lower stratosphere discussed earlier. Differences between retrieval and sonde, MLS 1, and MLS 2 data are illustrated with boxand-whisker plots (Fig. 5), which show the minimum and maximum difference (black dots), median (black line), average (red dot), interquartile (i.e. 25 th-75th percentile) range (box), and the 10th-90th percentile range (whiskers) for each layer or combination of layers. We also plotted statistics for the difference of the MLS 1 and MLS 2 data sets to indicate the variability of the actual ozone profile over the course of 1 day. Figure 5 includes results from spring and autumn combined. Table 2 provides statistics calculated separately for spring and autumn.

The first row (panels a-d) of Fig. 5 shows results calculated without the model and cloud corrections; $\sigma_{\mathrm{a}}$ was set to 0.4 . The average and median biases between retrieval and MLS data vary between -8 and $+5 \%$ (Fig. $5 b$ and c). The largest negative bias is observed for layers 5 and 6 , while the largest positive bias of $5 \%$ is observed closest to the surface (layer 2 and 3 ). Biases relative to the sonde measurements (Fig. 5a) are by and large consistent with biases relative to MLS data, although the comparatively small num- 
No model correction, no cloud correction, $\sigma_{\mathrm{a}}=0.4$
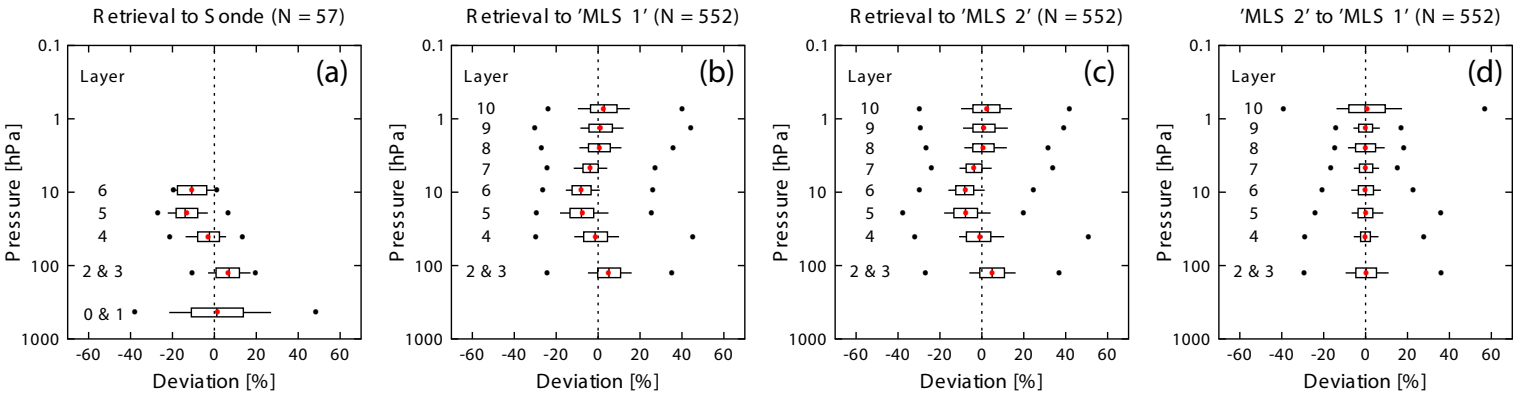

Model correction, no cloud correction, $\sigma_{\mathrm{a}}=0.4$
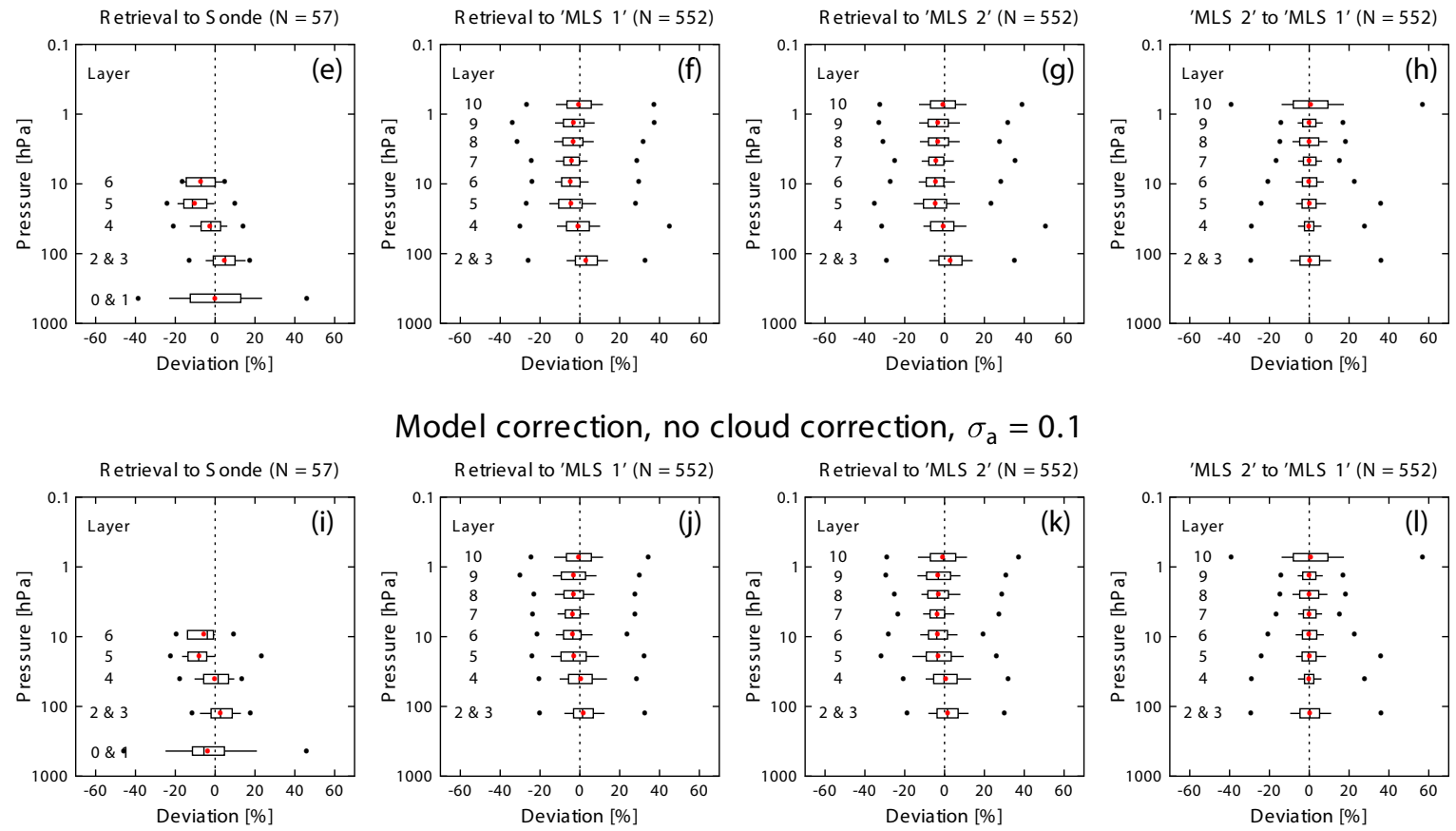

Model correction, cloud correction, $\sigma_{\mathrm{a}}=0.1$
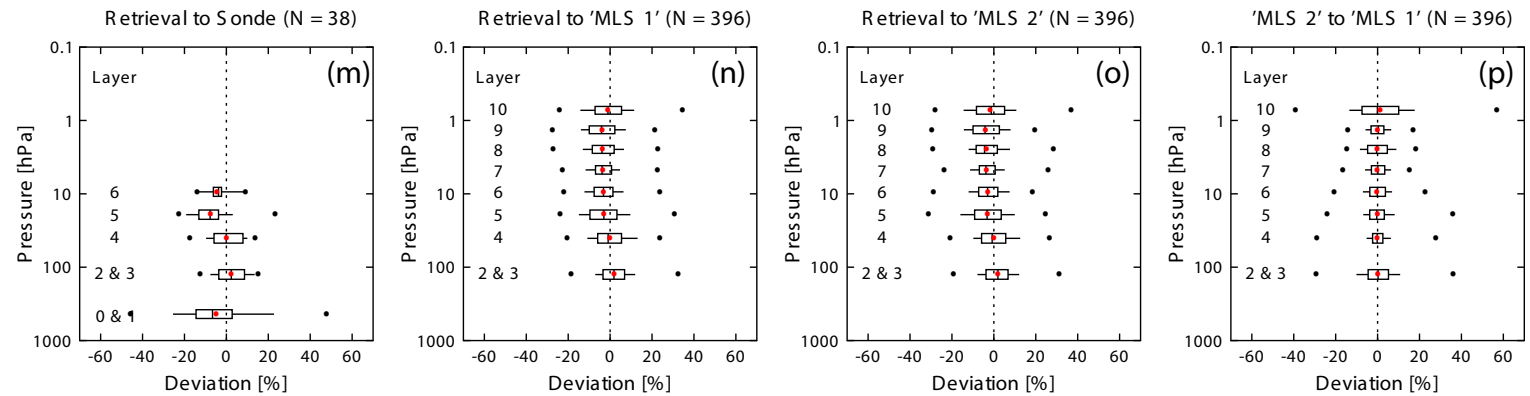

Figure 5. Box-and-whisker plots showing the difference between Umkehr retrieval results and sonde measurements (first column), MLS observations for day of retrieval (MLS 1 data set, second column), and MLS observations for the following day (MLS 2 data set, third column). The fourth column illustrates the difference between the MLS 2 and MLS 1 data sets. Each plot shows the minimum and maximum difference (black dots), median (black line), average (red dot) interquartile range (box) and the 10th-90th percentile range (whiskers) for each layer. Results for layers 0 and 1 and layers 2 and 3 were combined. The $\mathrm{N}$ in the headers of each plot indicates the number of profiles used for computing the statistics. Results in each row were calculated with a different set of parameters. First row (panels a-d): forward model not corrected, no cloud correction, $\sigma_{\mathrm{a}}=0.4$. Second row (panels $\mathbf{e}-\mathbf{h}$ ): forward model corrected by scaling with $1 / R(\theta)$, no cloud correction, $\sigma_{\mathrm{a}}=0.4$. Third row (panels $\mathbf{i}-\mathbf{l}$ ): forward model corrected, no cloud correction, $\sigma_{\mathrm{a}}=0.1$. Fourth row (panels $\mathbf{m}-\mathbf{p}$ ): forward model corrected, cloud correction using data of photodiode, $\sigma_{\mathrm{a}}=0.1$. 
Table 2. Bias and interquartile range (in parenthesis) of retrieval-MLS 1 comparison, average and SD of the difference between total ozone calculated from retrieved profiles and measured by OMI (TOC), and average number of degrees of freedom for signal ( $\left.\left\langle d_{\mathrm{S}}\right\rangle\right)$ for spring and autumn periods. The second column provides the number of profiles $(N)$ contributing to the statistics.

\begin{tabular}{|c|c|c|c|c|c|c|c|c|c|c|c|}
\hline \multirow[t]{2}{*}{ Season } & \multirow[t]{2}{*}{$N$} & \multicolumn{8}{|c|}{ Bias and interquartile range of retrieval-MLS 1 comparison for layer } & \multirow[t]{2}{*}{ TOC } & \multirow[t]{2}{*}{$\left\langle d_{\mathrm{s}}\right\rangle$} \\
\hline & & $2 \& 3$ & 4 & 5 & 6 & 7 & 8 & 9 & 10 & & \\
\hline \multicolumn{12}{|c|}{ No model correction, no cloud correction, $\sigma_{\mathrm{a}}=0.4$} \\
\hline Spring & 197 & $4 \%(14 \%)$ & $-1 \%(10 \%)$ & $-8 \%(9 \%)$ & $-10 \%(8 \%)$ & $-4 \%(9 \%)$ & $-1 \%(11 \%)$ & $0 \%(10 \%)$ & $4 \%(15 \%)$ & $0.2 \%(1.9 \%)$ & 3.1 \\
\hline Autumn & 355 & $6 \%(10 \%)$ & $-1 \%(12 \%)$ & $-8 \%(12 \%)$ & $-7 \%(9 \%)$ & $-3 \%(7 \%)$ & $1 \%(9 \%)$ & $1 \%(11 \%)$ & $3 \%(11 \%)$ & $0.7 \%(1.8 \%)$ & 3.0 \\
\hline \multicolumn{12}{|c|}{ Model correction, no cloud correction, $\sigma_{\mathrm{a}}=0.4$} \\
\hline Spring & 197 & $2 \%(13 \%)$ & $-1 \%(10 \%)$ & $-6 \%(10 \%)$ & $-6 \%(8 \%)$ & $-4 \%(10 \%)$ & $-5 \%(11 \%)$ & $-5 \%(10 \%)$ & $0 \%(14 \%)$ & $0.0 \%(1.9 \%)$ & 3.1 \\
\hline Autumn & 355 & $4 \%(10 \%)$ & $-1 \%(12 \%)$ & $-4 \%(13 \%)$ & $-4 \%(9 \%)$ & $-4 \%(7 \%)$ & $-3 \%(9 \%)$ & $-3 \%(11 \%)$ & $0 \%(11 \%)$ & $0.5 \%(1.8 \%)$ & 3.0 \\
\hline \multicolumn{12}{|c|}{ Model correction, cloud correction, $\sigma_{\mathrm{a}}=0.4$} \\
\hline Spring & 142 & $3 \%(13 \%)$ & $-2 \%(12 \%)$ & $-6 \%(10 \%)$ & $-6 \%(8 \%)$ & $-5 \%(10 \%)$ & $-6 \%(12 \%)$ & $-6 \%(10 \%)$ & $-1 \%(15 \%)$ & $0.0 \%(2.0 \%)$ & 3.1 \\
\hline Autumn & 254 & $3 \%(10 \%)$ & $-1 \%(11 \%)$ & $-4 \%(12 \%)$ & $-3 \%(9 \%)$ & $-4 \%(8 \%)$ & $-3 \%(10 \%)$ & $-3 \%(10 \%)$ & $-1 \%(11 \%)$ & $0.5 \%(1.9 \%)$ & 3.0 \\
\hline \multicolumn{12}{|c|}{ Model correction, no cloud correction, $\sigma_{\mathrm{a}}=0.1$} \\
\hline Spring & 197 & $1 \%(12 \%)$ & $-1 \%(12 \%)$ & $-4 \%(12 \%)$ & $-5 \%(10 \%)$ & $-4 \%(10 \%)$ & $-4 \%(12 \%)$ & $-4 \%(13 \%)$ & $1 \%(14 \%)$ & $-0.2 \%(1.8 \%)$ & 2.2 \\
\hline Autumn & 355 & $2 \%(9 \%)$ & $0 \%(12 \%)$ & $-3 \%(14 \%)$ & $-3 \%(8 \%)$ & $-4 \%(7 \%)$ & $-3 \%(9 \%)$ & $-3 \%(12 \%)$ & $0 \%(12 \%)$ & $0.3 \%(1.7 \%)$ & 2.1 \\
\hline \multicolumn{12}{|c|}{ Model correction, cloud correction, $\sigma_{\mathrm{a}}=0.1$} \\
\hline Spring & 142 & $1 \%(12 \%)$ & $-1 \%(13 \%)$ & $-4 \%(12 \%)$ & $-5 \%(10 \%)$ & $-4 \%(11 \%)$ & $-4 \%(12 \%)$ & $-5 \%(13 \%)$ & $-1 \%(16 \%)$ & $-0.2 \%(1.9 \%)$ & 2.2 \\
\hline Autumn & 254 & $2 \%(8 \%)$ & $-1 \%(11 \%)$ & $-2 \%(14 \%)$ & $-2 \%(8 \%)$ & $-3 \%(7 \%)$ & $-4 \%(9 \%)$ & $-4 \%(12 \%)$ & $-1 \%(11 \%)$ & $0.3 \%(1.7 \%)$ & 2.1 \\
\hline
\end{tabular}

ber of sonde observations makes the statistics less robust. Figure $5 \mathrm{~d}$ confirms that there is no systematic difference between the MLS measurements on the day of Umkehr observations (MLS 1) and the following day (MLS 2).

For the retrieval-MLS comparisons, the interquartile ranges vary between 7 and $12 \%$ and depend only modestly on the layer. With the exception of the results for the highest layer, the interquartile ranges for the MLS 2-MLS $1 \mathrm{com}$ parison vary between 5 and $10 \%$. Differences between the 10th and 90th percentiles vary between 14 and $24 \%$ for the retrieval-MLS comparisons (whiskers in Fig. 5b and c) and between 12 and $17 \%$ for the MLS 2-MLS 1 comparison, excluding the highest layer (Fig. 5d). The similarity of the ranges for the retrieval-MLS and MLS 2-MLS 1 comparisons suggests that a large portion of the observed retrievalMLS differences can be attributed to changes in the actual ozone profile over the time periods relevant for these comparisons. Lastly, the large interquartile range for the retrievalsonde comparison observed in layer 0 and 1 (Fig. 5a) is again a manifestation of the fact that the Umkehr method has little sensitivity for the layers closest to the surface.

To assess the effect of the forward model correction on our Umkehr retrievals, we repeated the calculations with this correction. Results are presented in the second row (panels e-h) of Fig. 5. As before, no cloud correction was applied and $\sigma_{\mathrm{a}}$ was set to 0.4. By comparing the original results (Fig. 5b and c) with the corrected results (Fig. $5 f$ and g) it can be observed that the bias between retrieval and MLS data has diminished and now varies between $-5 \%$ (layers 5 and 6 ) and $+3 \%$ (layers 2 and 3), suggesting that the model correction is justified. The interquartile ranges with and without the correction are virtually indistinguishable. Note that the cor- rection has no effect on the MLS 2-MLS 1 comparison and Fig. $5 \mathrm{~d}$ and $\mathrm{h}$ are therefore identical.

To explore the effect of $\sigma_{\mathrm{a}}$ on the results, we repeated the calculations using $\sigma_{\mathrm{a}}=0.1$ instead of $\sigma_{\mathrm{a}}=0.4$. Results are shown in the third row (panels i-l) of Fig. 5. For $\sigma_{\mathrm{a}}=0.1$, the bias between retrieval and MLS data has decreased further and now varies between -4 and $+1 \%$ (Fig. $5 \mathrm{j}$ and k). Differences between retrieval and sondes (Fig. 5i) have also decreased compared to calculations with $\sigma_{\mathrm{a}}=0.4$, except for layer 0 and 1 . The observation that biases are larger for a larger value of $\sigma_{\mathrm{a}}$ could be caused by systematic errors in the measurement vector or an incomplete correction of the forward model results. Changing $\sigma_{\mathrm{a}}$ from 0.4 to 0.1 had almost no effect on the interquartile range. However, minimum and maximum differences (black dots) contracted somewhat.

Finally, the calculations were repeated with the cloud correction turned on (fourth row of Fig. 5, panels m-p). For the retrieval-MLS comparison, biases and interquartile ranges with and without the cloud correction agree to within $1 \%$. Results for the retrieval to sonde comparison (Fig. 5m) are affected by the small sample size of $N=38$. (Note that results shown for Layer 6 are only based on eight samples because most balloons burst before they reach this layer.)

The difference between uncorrected and cloud-corrected statistics is very small, suggesting that clouds affect the accuracy of the retrievals only marginally. However, this conclusion may not apply to locations with thicker clouds and should be tested if the method is used at other sites.

Table 2 allows the assessment of retrievals for spring and autumn periods separately. Because statistics are more robust for the retrieval-MLS than retrieval-sonde comparisons, Table 2 only presents results for the former. Biases and in- 
terquartile ranges are provided with and without the model and cloud corrections, and with $\sigma_{\mathrm{a}}$ set to either 0.4 or 0.1 . Biases for spring and autumn agree to within $3 \%$ for all layers. When no corrections are applied and $\sigma_{\mathrm{a}}=0.4$, biases range between $-10 \%$ (Layer 6 for spring) and $+6 \%$ (layers 2 and 3 for autumn). The model correction decreases this range to between -6 and $4 \%$. By reducing $\sigma_{\mathrm{a}}$ from 0.4 to 0.1 , the range decreases further to between -5 to $2 \%$. The cloud correction has a negligible $(\leq 1 \%)$ effect on the biases. Interquartile ranges vary from 7 to $16 \%$ and depend only little $(\leq 3 \%)$ on $\sigma_{\mathrm{a}}$ and on whether or not corrections are applied.

Table 2 also includes a column comparing TOCs derived from the retrieved profiles with measurements by OMI. Depending on $\sigma_{\mathrm{a}}$ and the correction method, the average difference between the retrieved and OMI TOCs varies between -0.2 and $0.7 \%$, and the SD varies between 1.7 and $2.0 \%$.

Lastly, the average value of $d_{\mathrm{s}}$ is about 3.0 for $\sigma_{\mathrm{a}}=0.4$ and 2.1 for $\sigma_{\mathrm{a}}=0.1$. A value of $d_{\mathrm{s}}=3.0$ may seem low, but it is consistent with values of $d_{\mathrm{S}}$ resulting from the standard zenith-sky Umkehr technique. For example, Stone et al. (2015) reported a value of $d_{\mathrm{s}}=3.1$ for Dobson zenithsky Umkehr retrievals using the Dobson $\mathrm{C}$ wavelength pair (311.4 and $332.4 \mathrm{~nm}$ ) and the standard Dobson SZAs ranging from 60 to $90^{\circ}$.

\section{Discussion}

When the forward model is corrected, the bias of our retrievals relative to MLS data is smaller than $\pm 6 \%$ for all layers. This level of agreement compares favourably with published results of the standard zenith-sky Umkehr method. For example, McElroy and Kerr (1995) compared Umkehr profiles derived from a Brewer spectrophotometer with concurrent measurements of a lidar, a microwave radiometer and ozone sondes, which were performed during a 1-month campaign at the Table Mountain Observatory in California. The mean bias between the Brewer zenith-sky Umkehr results and the mean of the other instruments varied to within $\pm 10 \%$ for altitudes between 20 and $35 \mathrm{~km}$. Between 37 and $47 \mathrm{~km}$, the Brewer data were low by 15 to $20 \%$ (Fig. 9 of McElroy and Kerr, 1995).

Nair et al. (2011) compared stratospheric ozone vertical distribution measured by a large number of ground-based and satellite sensors at the Haute-Provence Observatory, France. They found that zenith-sky Umkehr data from an automated Dobson spectrophotometer systematically underestimate the stratospheric ozone concentration with a near-zero bias at about $30 \mathrm{~km}$, but increase to $7 \%$ at 21 and $34 \mathrm{~km}$, and to $14 \%$ at $40 \mathrm{~km}$ (Fig. 8 of Nair et al., 2011). Despite these large biases, Nair et al. (2011) concluded that Umkehr data are useful for studies of long-term ozone evolution and for detecting drifts in satellite observations.

Miyagawa et al. (2014) compared Dobson zenith-sky Umkehr measurements with homogenized NOAA SBUV
(Solar Backscatter Ultraviolet instrument) (/2) 8.6 overpass data measured between 1977 and 2011. The mean bias between Dobson and SBUV partial ozone column varied between $-12 \%$ for Layer 7 and $+3 \%$ for Layer 2 (Fig. 1a of Miyagawa et al., 2014).

The biases reported in the three studies quoted above are comparable or larger than the differences between our Global-Umkehr retrievals and MLS and sonde measurements, suggesting that Umkehr results derived from global spectral irradiance can provide data with similar accuracy to the established zenith-sky method. A portion of the retrievalMLS difference could also be caused by systematic errors in the MLS data set, considering that the MLS accuracy specified by Froidevaux et al. (2008) is in the 5 to $10 \%$ range.

Results presented in Fig. 5 illustrate that interquartile and 10th-90th percentile ranges for the retrieval-MLS comparison on one hand and the MLS 2-MLS 1 comparison on the other are similar for most layers. This suggests that a large portion of the observed retrieval-MLS differences can be attributed to actual changes in the ozone profile over the time periods relevant for these comparisons. However, a portion of the change in the MLS profile from one day to the next may be caused by the relatively poor horizontal resolution of MLS profiles of about $200 \mathrm{~km}$. In addition, some variability in the MLS data set can be attributed to the slightly different geolocations of two consecutive overpass profiles. For example, the average horizontal distance between the locations of Summit and the MLS overpass is $160 \mathrm{~km}$. Further analysis revealed that the difference between the MLS 1 and MLS 2 data sets also depends on the time at which the daily MLS observation takes place. For example, when MLS 2 data are from the observation period close to local solar noon (14:11 to $15: 10$ UTC) and MLS 1 data are measured close to sunrise (05:28 to 06:26 UTC), MLS 2 data for layers 7-9 have a high bias of 3-6\% relative to the MLS 1 data set, while MLS 2 data for Layer 10 have a low bias of $8 \%$. This timeof-day dependency and its variation with altitude is by and large consistent with diurnal variations of the ozone profile measured by various instruments at Mauna Loa, Hawaii (Parrish et al., 2014), and by a microwave radiometer at Bern, Switzerland (Studer et al., 2014). This suggests that the timeof-day effect observed at Summit is caused by actual diurnal changes of the ozone profile rather than potential timedependent systematic errors in the MLS data set.

Another source of variability in the retrieval-MLS and retrieval-sonde comparisons is the different vertical resolutions of MLS (about $2-3 \mathrm{~km}$ ), sondes $(0.1 \mathrm{~km})$, and our Umkehr retrievals (about $10 \mathrm{~km}$ for $\sigma_{\mathrm{a}}=0.4$ and about $25 \mathrm{~km}$ for $\sigma_{\mathrm{a}}=0.1$ ). If the measurements and forward model were without error, an Umkehr profile would resemble the actual profile smoothed by the AKs. To reduce the effect of the differing resolution, the higher-resolution MLS profiles could be convolved with the AKs of the Umkehr profile prior to comparing the two profiles. This technique has been applied by Nair et al. (2011) when comparing lidar and SBUV pro- 
files. We did not use this method because it artificially reduces the true difference that is observed when comparing a high-resolution profile (sonde, MLS) with a low-resolution (Umkehr) profile. Nair et al. (2011) found that the smoothing technique does not make a significant difference to seasonally averaged data such as those presented in Fig. 5 and Table 2.

The bias between Umkehr retrievals and MLS or sonde data is reduced when correcting the forward model for the systematic error presented by the pseudospherical approximation. It is interesting to note that the correction is only in the -0.5 to $2.0 \%$ range (Fig. 1b) but reduces the retrieval bias by up to $4 \%$ (Layer 6 in spring; see Table 2). Considering that the uncertainty of our measurements is $3 \%(1 \sigma)$, systematic errors in the measurement vector in the $2-3 \%$ range could conceivably be responsible for the remaining bias of Umkehr and MLS profiles indicated in Fig. 5 and Table 2. To test this hypothesis, we modified the measurement vector within reasonable limits and recalculated the profiles. We found that the bias between Umkehr and MLS profiles cannot be significantly reduced further, suggesting that the bias cannot be attributed to measurement errors alone.

The difference between results corrected for cloud effects and uncorrected results is very small, implying that clouds affect the accuracy of the retrievals only marginally. However, this conclusion may not apply to locations with thicker clouds or locations affected by aerosols and should be tested if the method is used at other sites.

If $\mathbf{S}_{\varepsilon}$ is well defined, the most important parameter that optimizes the results is $\sigma_{\mathrm{a}}$. The objective is to find the right balance between sensitivity to the a priori profile on one hand and sensitivity to (unavoidable) errors in the measurement vector or forward model on the other. We chose $\sigma_{\mathrm{a}}=0.1$ and 0.4. The smaller value quantifies the SD of the actual variability of the ozone profile at Summit. While calculations with this value lead to good results, the solution may not be optimal for profiles at the fringe of the distribution (e.g. result for Layer 3 in Fig. 3). A small $\sigma_{\mathrm{a}}$ also results in a small value of $d_{\mathrm{s}}$. However, statistics for results calculated with $\sigma_{\mathrm{a}}=0.1$ and 0.4 are quite similar (Table 2), suggesting that any value for $\sigma_{\mathrm{a}}$ between 0.1 and 0.4 leads to acceptable profiles. Determining the best value for sites other than Summit requires consideration of the measurement system and variability of the ozone profile at this site.

There are various ways to optimize the Global-Umkehr method for specific applications or locations. For example, if two instruments were to take measurements side by side, the uncertainty used to set up $\mathbf{S}_{\varepsilon}$ could be better estimated by comparing the measurements of the two systems. Furthermore, the method to set up $\mathbf{S}_{\mathrm{a}}$ could be modified to take into account the dependence of the variability of the ozone profile on altitude (Eq. 4 uses the same SD $\sigma_{\mathrm{a}}$ for all layers). Ozone absorption cross section data could be used (e.g. Orphal et al., 2016) that are more current than the Bass and Paur (1985) data implemented in this work and by OMI. If tem- perature profile data are available, these could be utilized to account for the temperature dependence of the ozone absorption cross section. Wavelengths, bandpass, and SZAs used for the measurement vector could be further optimized to reduce uncertainties related to the Ring effect or the temperature dependence of the ozone absorption cross section. For example, by degrading the spectral resolution (currently set to $2 \mathrm{~nm}$ ), the impact of the Ring effect could be diminished. Finally, the MYSTIC Monte Carlo model, which was used to calculate the correction function $R(\theta)$ (see Fig. 1b), was run with a scalar radiative transfer solver, which did not take polarization into account. Lacis et al. (1998) calculated that modelling errors for irradiance resulting from the omission of polarization in these calculations can be as large as $1.3 \%$ for a Rayleigh atmosphere. However, errors for 310 and $337 \mathrm{~nm}$ (i.e. the wavelengths used in the Global-Umkehr method) agree to within $0.1 \%$. We therefore conclude that the omission of polarization is not an import error source in our calculations.

We used a priori profiles that are independent of the total ozone column. Zenith-sky Umkehr retrievals from Dobson instruments that have historically been processed with the algorithm developed by Mateer and DeLuisi (1992) used TOCdependent a priori profiles to constrain the retrieval. While this practice can lead to artefacts when calculating trends (Petropavlovskikh et al., 2005; Stone et al., 2015), the approach may be the best choice if a profile with the smallest uncertainty possible is sought for a specific purpose.

The Global-Umkehr method was tested with spectroradiometric measurements from a polar location because we only operate instruments at high-latitude sites. Inversions using high-latitude data are more challenging compared to retrievals for lower latitudes because of the limited range of SZAs at polar regions, the long time that is required to scan the range of SZAs necessary for the retrieval, and the high short- and long-term variability of the ozone profile. We therefore have confidence that the method would work well for midlatitude and low-latitude locations. Confirmation of this assertion is subject to future tests.

\section{Conclusions}

An optimal estimation method has been developed to retrieve vertical ozone profiles from measurements of global spectral irradiance in the UV. The method is similar to the widely used zenith-sky Umkehr technique, which inverts measurements of zenith sky radiance. To our knowledge, this is the first time that the Umkehr technique was applied to measurements of global irradiance. High-quality measurements of global spectral irradiance are now available for more than 25 years at several NDACC locations (De Mazière et al., 2017), and the Global-Umkehr method has the potential to make these long-term data sets available for studying changes in the vertical distribution of ozone. 
Compared to the standard zenith-sky Umkehr method, multiple scattering effects become more important when exploiting global irradiance measurements, which also include contributions from photons received from directions close to the horizon. Therefore, the sphericity of the viewing geometry needs to be taken into account. We have shown that this challenge can be overcome by using a forward model with pseudospherical approximation plus additional corrections.

The method was evaluated with spectroradiometric measurements from Summit, Greenland, and validated with balloon-sonde and MLS observations. For calculations using the corrected forward model, the bias between our retrieved profiles and MLS observations ranges between $-5 \%$ (layers 5 and 6 ) and $+3 \%$ (layers 2 and 3). The magnitude of this bias is comparable, if not smaller, to values reported in the literature for the standard zenith-sky Umkehr method. The distribution of the difference between retrieval and MLS observations was quantified with the interquartile and 10th90th percentile ranges. Depending on altitude, the interquartile ranges vary between 7 and $13 \%$ and the 10th-90th percentile ranges run between 14 and $24 \%$. Interquartile ranges calculated from the differences of two MLS profiles that were measured on consecutive days vary between 5 and $10 \%$, suggesting that a considerable portion of the retrieval-MLS differences can be attributed to real changes in the ozone profile. For Umkehr layers 2 and higher, retrieval-MLS and retrieval-sonde differences are by and large consistent. The poor sensitivity of the Umkehr method to the altitude range of layer 0 and 1 leads to relatively large scatter (e.g. the interquartile range is $25 \%$ ) of the retrieval-sonde differences for this layer.

The effect of the parameter $\sigma_{\mathrm{a}}$, which controls the sensitivity of the solution on the a priori profile, was extensively assessed. It was found that results calculated with a small value of $\sigma_{\mathrm{a}}=0.1$ (emphasis on a priori) generally agree to within $2-3 \%$ of those calculated with a large value of $\sigma_{\mathrm{a}}=0.4$ (emphasis on measurements). By setting $\sigma_{\mathrm{a}}$ to a large value, retrieval errors may occasionally become large if the measurement vector is affected by unforeseen conditions (e.g. changing ozone, variable clouds). For example, the maximum retrieval-MLS difference was $50 \%$ for $\sigma_{\mathrm{a}}=0.4$ but only $32 \%$ for $\sigma_{\mathrm{a}}=0.1$.

The retrieved ozone profiles were integrated over altitude. The resulting TOCs agreed almost perfectly with TOCs measured by OMI: depending on the correction method, the retrieval/OMI bias ranged between -0.2 and $0.7 \%$ with a SD of less than $2.0 \%$.

While the Global-Umkehr method was only tested for a high-latitude site, we are confident that it will also work at lower latitudes, but this assertion requires confirmation by future tests.
Data availability. Version 2 spectra from the SUV-150B spectroradiometer at Summit are available from the Arctic Data Center at https://arcticdata.io/. Profiles of ozone retrieved with the Global-Umkehr method are available at http://uv.biospherical.com/ Version2/data.asp.

Competing interests. The authors declare that they have no conflict of interest.

Acknowledgements. Funding for this study was provided by the US National Science Foundation's Office of Polar Programs Arctic Sciences Section (award ARC-1203250, Ultraviolet Radiation in the Arctic: 2012-2015). We are grateful to the numerous dedicated individuals who operated the UV radiometers at Summit. We also thank Bryan Johnson of NOAA for providing ozone profiles collected by balloon ozonesondes that were launched at Summit on a weekly bases. NSF provided funding for the ozonesonde measurements at Summit. We thank two anonymous reviewers for their thoughtful comments.

Edited by: Pawan K. Bhartia

Reviewed by: two anonymous referees

\section{References}

Anderson, G. P., Clough, S. A., Kneizys, F. X., Chetwynd, J. H., and Shettle, E. P.: AFGL atmospheric constituents profiles (0120 km), Tech. Rep. AFGL-TR-86-0110, Air Force Geophys. Lab., Hanscom Air Force Base, MA, 1986.

Bais, A. F., McKenzie, R. L., Bernhard, G., Aucamp, P. J., Ilyas, M., Madronich, S., and Tourpali, K.: Ozone depletion and climate change: impacts on UV radiation, Photochem. Photobio. S., 14, 19-52, 2015.

Bass, A. and Paur, R. J.: The ultraviolet cross sections of ozone: 1. The measurement, in: Atmospheric Ozone, edited by: Zerefos, C. and Ghazi, A., Springer, New York, 606-616, 1985.

Bernhard, G., Booth, C. R., and Ehramjian, J. C.: Version 2 data of the National Science Foundation's Ultraviolet Radiation Monitoring Network: South Pole, J. Geophys. Res.-Atmos., 109, D21207, https://doi.org/10.1029/2004JD004937, 2004.

Bernhard, G., Booth, C. R., and Ehramjian, J. C.: Comparison of UV irradiance measurements at Summit, Greenland; Barrow, Alaska; and South Pole, Antarctica, Atmos. Chem. Phys., 8, 4799-4810, https://doi.org/10.5194/acp-8-4799-2008, 2008.

Bhartia, P. K., McPeters, R. D., Flynn, L. E., Taylor, S., Kramarova, N. A., Frith, S., Fisher, B., and DeLand, M.: Solar Backscatter UV (SBUV) total ozone and profile algorithm, Atmos. Meas. Tech., 6, 2533-2548, https://doi.org/10.5194/amt-6-2533-2013, 2013.

Booth, C. R., Lucas, T. B., Morrow, J. H., Weiler, C. S., and Penhale, P. A.: The United States National Science Foundation's polar network for monitoring ultraviolet radiation, in: Ultraviolet Radiation in Antarctica: Measurement and Biological Effects, Antarct. Res. Ser., 62, edited by: Weiler, C. S. and Penhale, P. A., AGU, Washington DC, USA, 17-37, 1994. 
Carmagnola, C. M., Domine, F., Dumont, M., Wright, P., Strellis, B., Bergin, M., Dibb, J., Picard, G., Libois, Q., Arnaud, L., and Morin, S.: Snow spectral albedo at Summit, Greenland: measurements and numerical simulations based on physical and chemical properties of the snowpack, The Cryosphere, 7, 1139-1160, https://doi.org/10.5194/tc-7-1139-2013, 2013.

De Mazière, M., Thompson, A. M., Kurylo, M. J., Wild, J., Bernhard, G., Blumenstock, T., Hannigan, J., Lambert, J.-C., Leblanc, T., McGee, T. J., Nedoluha, G., Petropavlovskikh, I., Seckmeyer, G., Simon, P. C., Steinbrecht, W., Strahan, S., and Sullivan, J. T.: The Network for the Detection of Atmospheric Composition Change (NDACC): History, status and perspectives, Atmos. Chem. Phys. Discuss., https://doi.org/10.5194/acp2017-402, in review, 2017.

DeLuisi, J. J., Mateer, C. L., Theisen, D., Bhartia, P. K., Longenecker, D., and Chu, B.: Northern middle-latitude ozone profile features and trends observed by SBUV and Umkehr, 1979-1990, J. Geophys. Res.-Atmos., 99, 1890118908, https://doi.org/10.1029/94JD01518, 1994.

Dütsch, H. U.: Vertical ozone distribution from Umkehr observations, Arch. Meteor. Geophy. A, 11, 240-251, 1959.

Emde, C. and Mayer, B.: Simulation of solar radiation during a total eclipse: a challenge for radiative transfer, Atmos. Chem. Phys., 7, 2259-2270, https://doi.org/10.5194/acp-7-2259-2007, 2007.

Froidevaux, L. and 47 others: Validation of Aura Microwave Limb Sounder stratospheric ozone measurements, J. Geophys. Res.Atmos., 113, D15S20, https://doi.org/10.1029/2007JD008771, 2008.

Goering, C. D., L'Ecuyer, T. S., Stephens, G. L., Slusser, J. R., Scott, G., Davis, J., Barnard, J. C., and Madronich, S.: Simultaneous retrievals of column ozone and aerosol optical properties from direct and diffuse solar irradiance measurements, J. Geophys. Res.-Atmos., 110, D05204, https://doi.org/10.1029/2004JD005330, 2005.

Gorshelev, V., Serdyuchenko, A., Weber, M., Chehade, W., and Burrows, J. P.: High spectral resolution ozone absorption crosssections - Part 1: Measurements, data analysis and comparison with previous measurements around $293 \mathrm{~K}$, Atmos. Meas. Tech., 7, 609-624, https://doi.org/10.5194/amt-7-609-2014, 2014.

Götz, F., Meetham, A. R., and Dobson, G. B.: The vertical distribution of ozone in the atmosphere, Proc. R. Soc. Lon. Ser.-A, 145, 416-446, 1934.

Krzyścin, J. W. and Rajewska-Więch, B.: Trends in the ozone vertical distribution from the Umkehr observations at Belsk 1963-2007, Int. J. Remote Sens., 30, 3917-3926, https://doi.org/10.1080/01431160902821866, 2009.

Lacis, A. A., Chowdhary, J., Mishchenko, M. I., and Cairns, B.: Modeling errors in diffuse-sky radiation: vector vs. scalar treatment, Geophys. Res. Lett., 25, 135-138, 1998.

Mateer, C. L. and DeLuisi, J. J.: A new Umkehr inversion algorithm, J. Atmos. Terr. Phys., 54, 537-556, 1992.

Mayer, B., Kylling, A., Madronich, S., and Seckmeyer, G.: Enhanced absorption of UV irradiance due to multiple scattering in clouds: experimental evidence and theoretical expectation. J. Geophys. Res.-Atmos., 103, 31241-31254, 1998.

Mayer, B. and Kylling, A.: Technical note: The libRadtran software package for radiative transfer calculations - description and examples of use, Atmos. Chem. Phys., 5, 1855-1877, https://doi.org/10.5194/acp-5-1855-2005, 2005.
Mayer, B.: Radiative transfer in the cloudy atmosphere, in EPJ Web of Conferences, Vol. 1, 75-99, EDP Sciences, Les Ulis, France, 2009.

Mayer, B., Kylling, A., Emde, C., Buras, R., Hamann, U., Gasteiger, J., and Richter, B.: libRadtran user's guide, Version 2.0, available at http://www.libradtran.org/doc/libRadtran. pdf (last access: 14 December 2017), 2015.

McElroy, C. T. and Kerr, J. B.: Table mountain ozone intercomparison: Brewer ozone spectrophotometer Umkehr observations, J. Geophys. Res.-Atmos., 100, 9293-9300, 1995.

Megie, G., Allain, J. Y., Chanin, M. L., and Blamont, J. E.: Vertical profile of stratospheric ozone by lidar sounding from the ground, Nature, 270, 329-331, 1977.

Miller, A. J., Flynn, L. E., Hollandsworth, S. M., DeLuisi, J. J., Petropavlovskikh, I. V., Tiao, G. C., Reinsel, G. C., Wuebbles, D. J., Kerr, J., Nagatani, R. M., and Bishop, L.: Information content of Umkehr and solar backscattered ultraviolet (SBUV) 2 satellite data for ozone trends and solar responses in the stratosphere, J. Geophys. Res.-Atmos., 102, 19257-19263, https://doi.org/10.1029/97JD01482, 1997.

Miyagawa, K., Petropavlovskikh, I., Evans, R. D., Long, C., Wild, J., Manney, G. L., and Daffer, W. H.: Long-term changes in the upper stratospheric ozone at Syowa, Antarctica, Atmos. Chem. Phys., 14, 3945-3968, https://doi.org/10.5194/acp-143945-2014, 2014.

Nair, P. J., Godin-Beekmann, S., Pazmiño, A., Hauchecorne, A., Ancellet, G., Petropavlovskikh, I., Flynn, L. E., and Froidevaux, L.: Coherence of long-term stratospheric ozone vertical distribution time series used for the study of ozone recovery at a northern mid-latitude station, Atmos. Chem. Phys., 11, 4957-4975, https://doi.org/10.5194/acp-11-4957-2011, 2011.

Newchurch, M. J., Grams, G. W., Cunnold, D. M., and DeLuisi, J. J.: A comparison of SAGE 1, SBUV, and Umkehr ozone profiles including a search for Umkehr aerosol effects, J. Geophys. Res.-Atmos., 92, 8382-8390, https://doi.org/10.1029/JD092iD07p08382, 1987.

Oltmans, S. J., Johnson, B., Vasel, B., Schnell, R., and Helmig, D.: Ozone over Summit, Greenland, presented at State Of the Arctic, 17 March 2010, Miami, FL, available at: http://soa.arcus.org/abstracts/ ozone-summit-greenland-seen-surface-and-profile-observations (last access: 14 December 2017), 2010.

Orphal, J., Staehelin, J., Tamminen, J., Braathen, G., De Backer, M. R., Bais, A., Balis, D., Barbe, A., Bhartia, P. K., Birk, M., and Burkholder, J. B.: Absorption crosssections of ozone in the ultraviolet and visible spectral regions: status report 2015, J. Mol. Spectrosc., 327, 105-121, https://doi.org/10.1016/j.jms.2016.07.007, 2016.

Parrish, A., Connor, B. J., Tsou, J. J., McDermid, I. S., and Chu, W. P.: Ground-based microwave monitoring of stratospheric ozone, J. Geophys. Res.-Atmos., 97, 2541-2546, 1992.

Parrish, A., Boyd, I. S., Nedoluha, G. E., Bhartia, P. K., Frith, S. M., Kramarova, N. A., Connor, B. J., Bodeker, G. E., Froidevaux, L., Shiotani, M., and Sakazaki, T.: Diurnal variations of stratospheric ozone measured by ground-based microwave remote sensing at the Mauna Loa NDACC site: measurement validation and GEOSCCM model comparison, Atmos. Chem. Phys., 14, 7255-7272, https://doi.org/10.5194/acp-14-7255-2014, 2014. 
Petropavlovskikh, I., Loughman, R., DeLuisi, J., and Herman, B.: A comparison of UV intensities calculated by sphericalatmosphere radiation transfer codes - application to the aerosol corrections, J. Geophys. Res.-Atmos., 105, 14737-14746, 2000.

Petropavlovskikh, I., Bhartia, P. K., and DeLuisi, J.: New Umkehr ozone profile retrieval algorithm optimized for climatological studies, Geophys. Res. Lett., 32, L16808, https://doi.org/10.1029/2005GL023323, 2005.

Petropavlovskikh, I., Evans, R., McConville, G., Oltmans, S., Quincy, D., Lantz, K., Disterhoft, P., Stanek, M., and Flynn, L.: Sensitivity of Dobson and Brewer Umkehr ozone profile retrievals to ozone cross-sections and stray light effects, Atmos. Meas. Tech., 4, 1841-1853, https://doi.org/10.5194/amt-4-18412011, 2011.

Rodgers, C. D.: Inverse Methods for Atmospheric Sounding: Theory and Practice, 238 pp., World Sci., Hackensack, NJ, 2000.

Seckmeyer, G., Erb, R., and Albold, A.: Transmittance of a cloud is wavelength-dependent in the UV-range, Geophys. Res. Lett., 23, 2753-2755, 1996.

Stone, K., Tully, M. B., Rhodes, S. K., and Schofield, R.: A new Dobson Umkehr ozone profile retrieval method optimising information content and resolution, Atmos. Meas. Tech., 8, 10431053, https://doi.org/10.5194/amt-8-1043-2015, 2015.
Studer, S., Hocke, K., Schanz, A., Schmidt, H., and Kämpfer, N.: A climatology of the diurnal variations in stratospheric and mesospheric ozone over Bern, Switzerland, Atmos. Chem. Phys., 14, 5905-5919, https://doi.org/10.5194/acp-14-5905-2014, 2014.

Tzortziou, M., Krotkov, N. A., Cede, A., Herman, J. R., and Vasilkov, A.: A new technique for retrieval of tropospheric and stratospheric ozone profiles using sky radiance measurements at multiple view angles: application to a Brewer spectrometer, J. Geophys. Res.-Atmos., 113, D06304, https://doi.org/10.1029/2007JD009093, 2008.

Waters, J. W., Froidevaux, L., Harwood, R. S., Jarnot, R. F., Pickett, H. M., Read, W. G., Siegel, P. H., E. Cofield, R. E., Filipiak, M. J., Flower, D. A., Holden, J. R., Lau, G. K., Livesey, N. J., Manney, G. L., Pumphrey, H. C., Santee, M. L., Wu, D. L., Cuddy, D. T., Lay, R. R., Loo, M. S., Perun, V. S., Schwartz, M. J., Stek, P. C., Thurstans, R. P., Boyles, M. A., Chandra, K. M., Chavez, M. C., Chen, G.-S., Chudasama, B. V., Dodge, R., Fuller, R. A., Girard, M. A., Jiang, J. H., Jiang, Y., Knosp, B. W., LaBelle, R. C., Lam, J. C., Lee, K. A., Miller, D., Oswald, J. E., Patel, N. C., Pukala, D. M., Quintero, O., Scaff, D. M., Van Snyder, W., Tope, M. C., Wagner, P. A., and Walch, M. J.: The earth observing system microwave limb sounder (EOS MLS) on the Aura satellite, IEEE T. Geosci. Remote, 44, 1075-1092, 2006. 